\title{
Project DISIRE (H2020) - an idea of annotating of ore with sensors in KGHM Polska Miedz S.A. underground copper ore mines
}

\author{
Witold Kawalec ${ }^{1, a}$, Robert Krol ${ }^{1}$, Radoslaw Zimroz ${ }^{1}$, Leszek Jurdziak ${ }^{1}$, Marek Jach ${ }^{2}$, Radoslaw Pilut ${ }^{3}$ \\ ${ }^{1}$ Wroclaw University of Technology, Wyb. Wyspiańskiego 27, 50-370 Wrocław, Poland \\ ${ }^{2}$ KGHM O/ZWR Polkowice, Kopalniana 1, 59-101 Polkowice, Poland \\ ${ }^{3}$ KGHM, M. Skłodowskiej-Curie 48, 59-301 Lubin, Poland
}

\begin{abstract}
The lithological composition of the copper ore delivered to the mills, when recognised in advance, is considered as the most important factor for the proper settings of grinding/milling equipment that can both decrease the specific energy consumption of ore processing and increase metal recovery. In order to address this problem, the idea of the use of sensors for in-situ sensing with respect to adaptation to harsh environment of copper ore conveying in the underground mines was investigated. The in-situ sensors information carrying pellets, are planned to be used for annotating the copper ore for the needs of ore processing plants control. The improved identification of the lithological composition of ore can be achieved by combination of annotating the stream of transported ore with pellets that keep the information on the original location of the ore (when they are dropped into the transported bulk material), the data of the in-situ lithology derived from the digital, orebody structural and quality block model and the simulation analysis of the transportation system. The idea is being developed within the DISIRE project - a part of the SPIRE initiative, acting under the "Horizon 2020" framework program.
\end{abstract}

\section{Introduction to the DISIRE project}

Sustainable Process Industry through Resource and Energy Efficiency (SPIRE) is a proposal for a Public Private Partnership (PPP) aiming to regain competitiveness of the ailing European process industry by "the collaborative efforts of public research and technology organisations and academia as well as industry stakeholders throughout Europe, along and across the value chain" $[5,6]$. The SPIRE initiative has been launched in order to address the European efficiency targets set for 2030:

- reduction in fossil energy intensity of up to $30 \%$ from current levels,

- up to $20 \%$ reduction in non-renewable, primary raw material intensity compared to current levels.

The DISIRE (Distributed In-Situ Sensors Integrated into Raw Material and Energy Feedstock) project belongs to the SPIRE 1 group - Integrated Process Control (IPC) and is aimed to "develop and introduce a technological platform for novel inline measurement techniques and Process Analyser Technology (PAT) sensors based IPC approach" $[4,6]$. The project consortium consists of 15 partners

\footnotetext{
${ }^{a}$ Corresponding author: witold.kawalec@pwr.edu.pl
} 
from Sweden, Spain, Italy, Germany, Poland and Israel. KGHM Polska Miedz S.A. (shortly called KGHM) is the key industrial partner of the Work Package 5 - Non-Ferrous Processes, focused on the improvement of transportation of the copper ore by belt conveyors and processing the ore as well as enhancement of the on-line PAT information on further process stages. Other industrial application work packages deal with ferrous, steel and combustion processes and are supported by the direct research and development activities in the areas of industrial process control, electronics and sensor development as well as data mining.

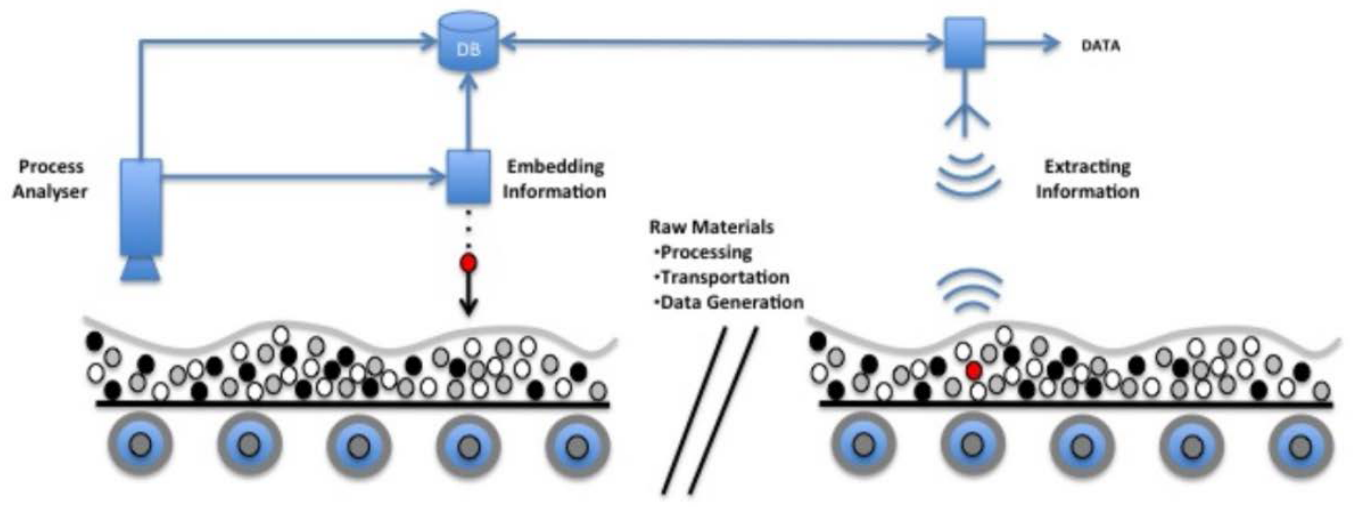

Figure 1. Application of the DISIRE concept in the pelletizing process [4].

The general idea of DISIRE concept is presented in Figure 1. The bulk material, usually undefined on either belt conveyor or a stockyard, is annotated with the help of pellets that are able to carry information. The information embedded into the pellets is obtained from a database supporting the process. As a result, either the transported or transformed bulk material keeps the information on itself, and if needed, on the process that can be read and analysed along its way in order to provide data for improving the consecutive steps of processing.

\section{Copper ore identification issues}

The problems identified in the copper ore processing at the KGHM processing plants have been addressed in several papers [3]. The authors of the review paper [1] stated that "The ore-treatment process of Polish copper-ores is difficult to proceed from when lithology changes and variability sizes of minerals are connected with an increase in energy consumption. As a result of this, finding new solutions in technology of concentration, new projects solutions are key elements to increasing the $\mathrm{Cu}$ concentrate grinding and flotation system productivity" [3]. As presented in Table 1 the lithology of copper ore is KGHM mines is different and changes throughout the years of mining. Authors [1] pointed that "the lithological types of ore treated by KGHM S.A. have not only variable crushing and grinding parameters, but also different floatability, which is the main reason for the creation of unique conditions for treatment during the grinding and flotation operations". The general lithological profile of the copper ore is presented in Fig. 1, but the proportions of thicknesses of each stratum are different from one mining field to another, and in some areas the given lithology can vanish completely.

The Polish resources are ones the most complex in the world, and additionally the most difficult to be processed. The main reasons for rating the Polish copper deposits as among the so-called difficult ones are due to the following factors [1]:

- relatively long flotation time as a result of slow kinetics of sulphide mineral particles,

- three lithological forms occur at the same time, but in different proportions, thus having a significant influence on the grinding and flotation conditions,

- $\quad$ fine and ultra-fine sulfide mineral particles require a fine grinding process. 


\section{Deposit's Vertical Profile}

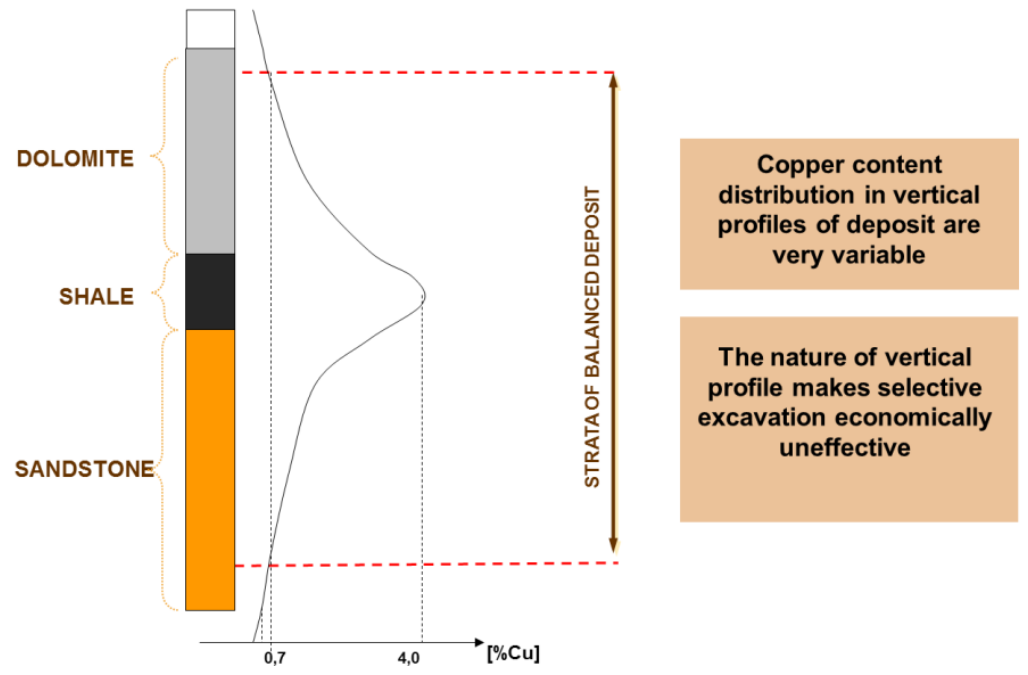

Figure 2. Structure and properties of copper ore deposit.

\section{Ore Textures}

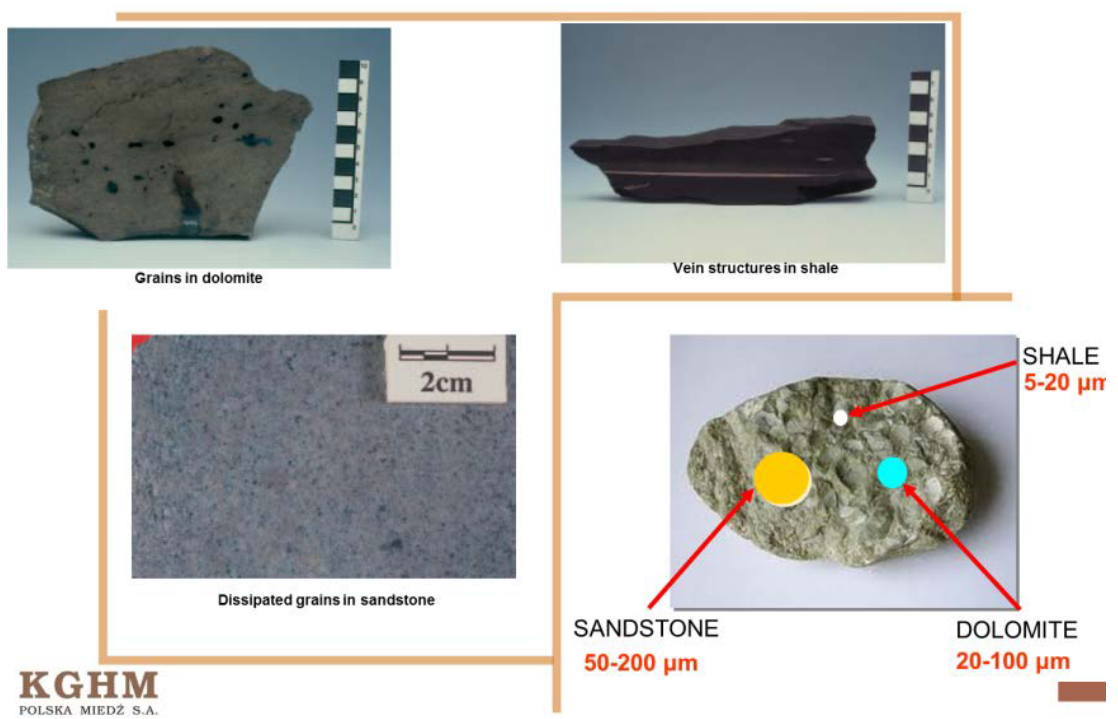

Figure 3. Types of texture of copper ore.

As shown in Figs. 2 and 3, the particles of copper ore are significantly differentiated in size according to the given lithology. Due to the available non-selective mining technology these particles are mixed when supplied to the processing plant. The average proportions of the ore lithology (see table 1) do not reflect the actual differences in mining fields (see Fig. 4). 
Table 1. KGHM S.A. deposit's changing of lithology structure [1].

\begin{tabular}{|c|c|c|c|c|c|c|}
\hline Concentrator name & \multicolumn{2}{|c|}{ Sandstone } & \multicolumn{2}{c|}{ Shale } & \multicolumn{2}{c|}{ Carbonates } \\
\cline { 2 - 7 } & Years & Years & Years & Years & Years & Years \\
& $1985-91$ & $2009-11$ & $1985-91$ & $2009-11$ & $1985-91$ & $2009-11$ \\
\hline Lubin & $54 \%$ & 77.545 & $8.1 \%$ & $0.94 \%$ & $37.9 \%$ & $21.52 \%$ \\
\hline Polkowice & $9.9 \%$ & $22.67 \%$ & $5.9 \%$ & $5.28 \%$ & $84.2 \%$ & $72.05 \%$ \\
\hline Rudna & $43.3 \%$ & $54.11 \%$ & $5.5 \%$ & $11.56 \%$ & $51.2 \%$ & $34.33 \%$ \\
\hline
\end{tabular}
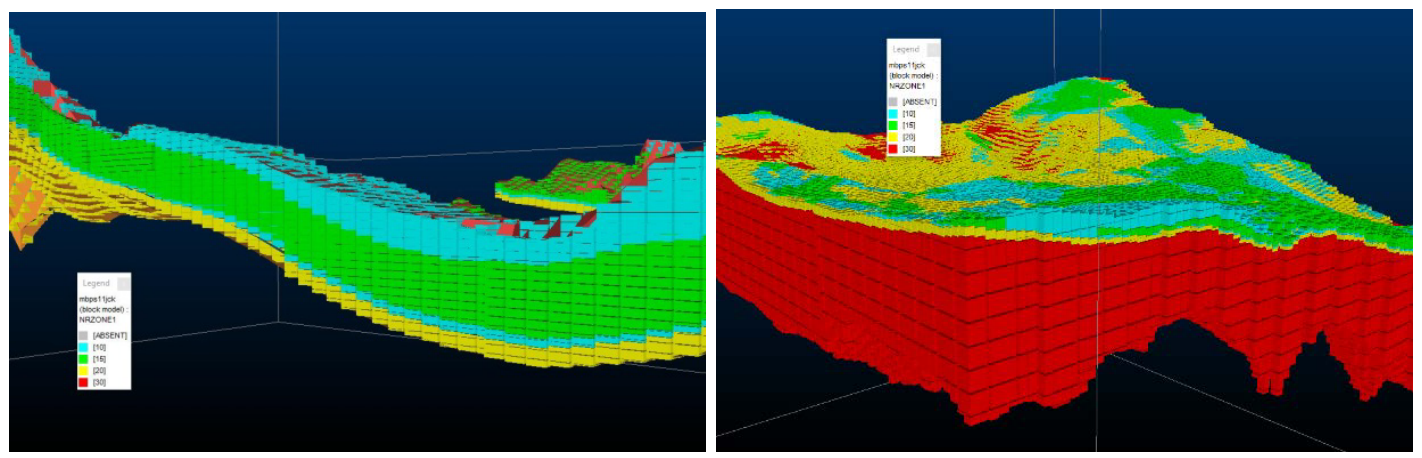

Figure 4. Visualisation of the structural block model of the balance ore from two mining fields of one KGHM Polska Miedz S.A. mine: left panel: carbonates (dolomites, streaky dolomites) and shale in the bottom, right panel: thin layer of shale on the top with sandstone (source: Datamine Studio).

\section{Proposal of a PAT solution}

\subsection{Prerequisites}

The DISIRE technology is targeted for the enhancement of existing information systems already implemented at KGHM, that could either provide required information to be embedded into pellets or process and analyse the information extracted thereafter. Is there a sufficient information environment in. mining and processing sites of KGHM?

KGHM successfully implements advanced information systems such as FloVis, MillVis and ConVis for supporting the complex processes of copper ore enrichment [2]. Especially the last one ConVis, designed for optimisation of managing and grinding of ore supplied from various mining fields, needs information on the lithology of ore to achieve the main targets of that is stabilization of ore granulation, optimisation of grinding and maintaining the stable crushed material flow onto mills feeders.

The second reason for considering implementation of DISIRE technology is the fact that KGHM undertook a project to upgrade the existing geological and mine planning systems into the full 3-D geological modelling and mine planning digital environment. The consulting division of CAE Mining (developer and distributer of Datamine software) was commissioned for this work and the training and implementation project was launched in 2015. It is expected that it leads to changes in methods used for data handling and to provide accurate, regularly updated information on the orebody as well as advancing mining fields (Fig. 6).

The last vital element of the existing information environment is managing and control the systems that support underground belt conveying (see Fig.5). These systems (containing also weights on 
selected conveyors) can provide the information on the actual operation status and load of each object of the transportation system.

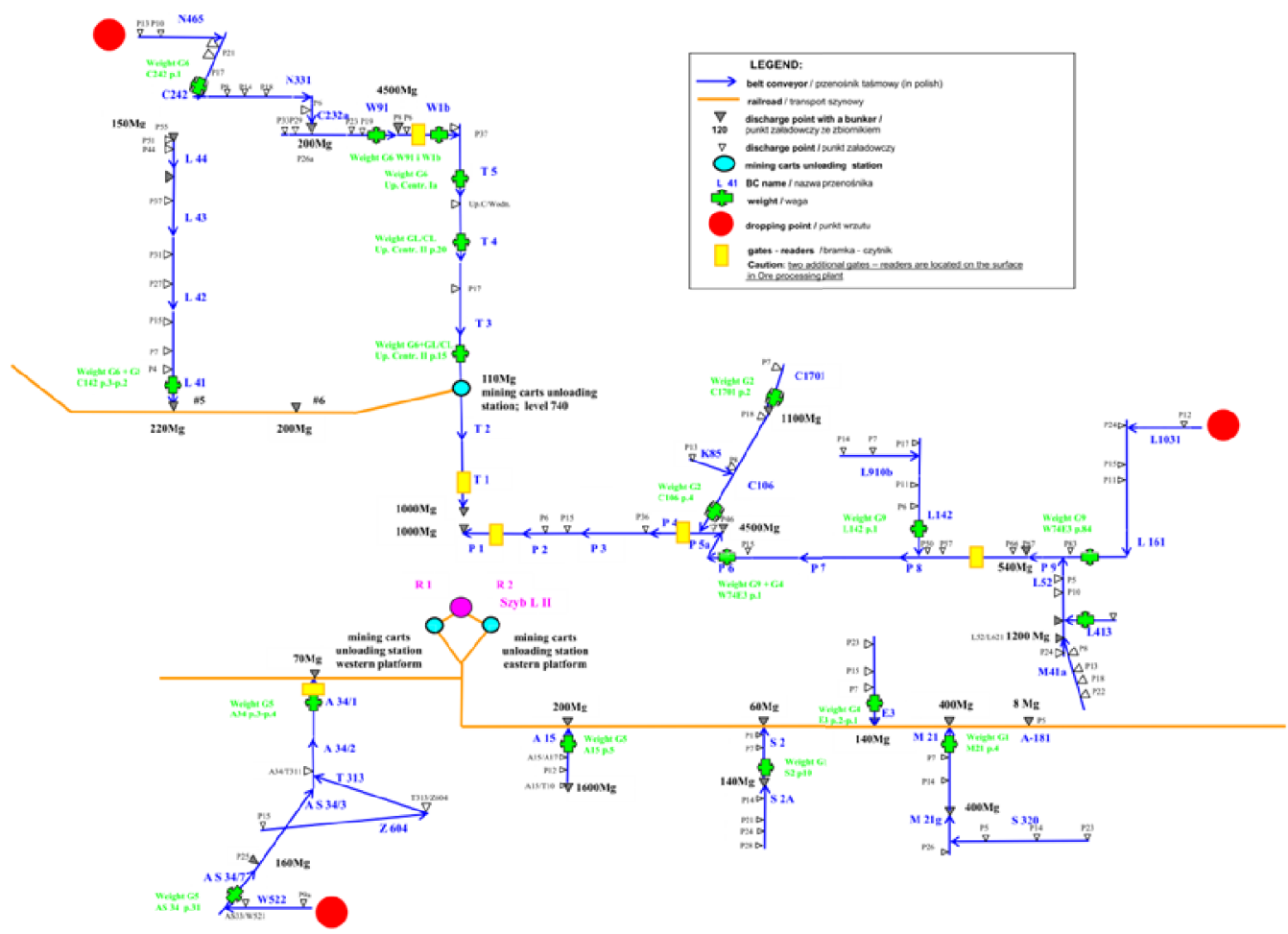

Figure 5. The underground transportation system in the "Lubin" mine of KGHM with the proposed locations of pellet dropping points (red bullet points) and pellet readers (yellow squares, 2 other are located on the surface on the entrance to the processing plant).
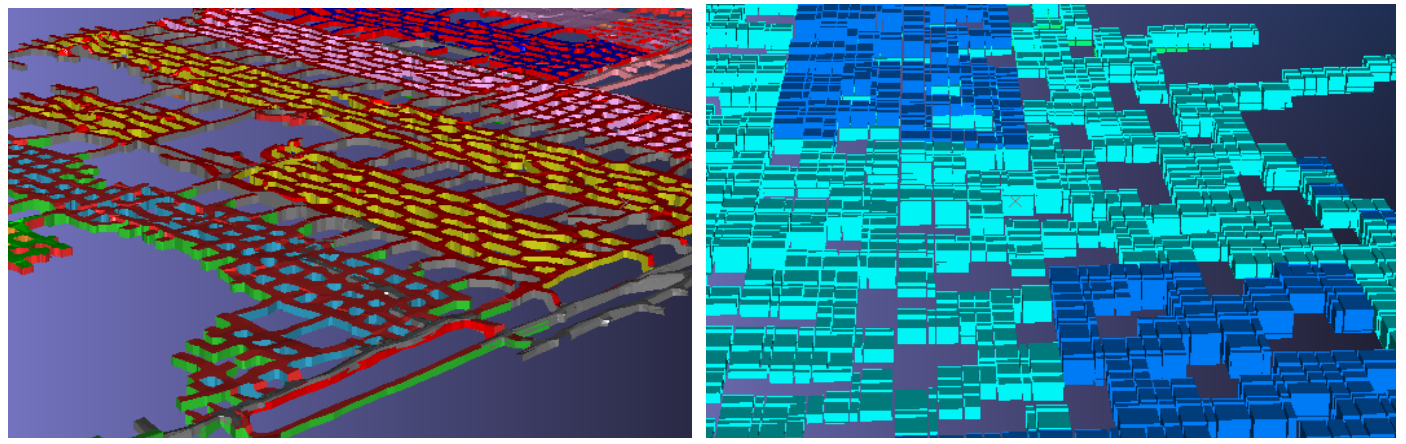

Figure 6. Typical visualisation of a digital 3-D model of underground room-and-pillar developments: left panel: solid wireframes, right panel: block model cells coloured by mining fields numbering (source: Datamine Studio).

\subsection{The DISIRE concept}

The proposal of the use of DISIRE pellets for tracking the ore in order to provide the suitable information on the processing plants assumes the following:

- pellets will be used to provide the information on lithology of the ore, 
- pellets are dropped into the copper ore bulk material while it is being discharged by eiter trucks or loaders onto the division belt conveyor loading point (Fig.5),

- pellets denote the place of mining field and consecutive number of discharging,

- $\quad$ pellets are read instantly after the portion of ore moved by a skip from the shafts the surface (Figs. 1 and 5).

The practical use of DISIRE pellets requires the interaction between the existing, currently being implemented and planned information systems. The 3-D geological modelling and mine planning system should provide the information on the lithology (Fig.4 and 6) on the basis of actual orebody structural model and location of the mining field. It is expected that the system would be on-line examined with annotation of the mining field read from the pellets delivered on the surface to return with the actual lithology composition at the mining faces obtained from the orebody model.

However, the composition of lithology of the ore moved to the surface depends on mixing of the ore from several mining fields. The assessment of this will be achieved with the use of read-in several pellets as well as information on the work of the underground transportation system.

It is not assumed that all pellets can survive transportation from the division belt conveyor to the surface under the difficult operational conditions of underground mines. The in-situ tests will allow to predict the percentage of pellets that are lost but it is obvious that the variance of "losses" will be high. Therefore, the result on lithology, based only on the weighted data from pellets, should be compared with the results of simulations of ore flow within the belt conveyor system.

The Convis system is expected to be fed with the data of lithology of ore that will be soon conveyed to the processing plant. The time delay caused by its transportation can be utilised for the proper adjustment of machinery equipment.

\section{Planned digital and in-situ investigations}

The DISIRE pellets project has just started. A series of experiments, both theoretical investigations and in-situ tests, are scheduled for the coming months.

The theoretical experiments include simulations of the belt conveyor systems. These are under development by domestic and foreign participants of the research consortium. It is assumed that the dedicated simulation software FlexSim (not exclusively) will be adopted for this purpose.

Another topic of investigation is concerned with interrogation of the modelling and mine planning system which has not been implemented yet. Though the needs of an experiment the query of the system can be simulated, the practical use require safe and regular on-line operations as well as keeping the orebody and mine advancing models updated.

The practical use of lithological information supplied in advance to the information systems supporting the processing plants can be verified by reviewing the procedures of setting the adjustments of processing machinery equipment. This can only be done by the specialists of KGHM processing divisions.

For the in-situ tests of dropping, transporting and reading pellets the dedicated equipment such as sufficiently ruggedized pellets and RFID gates for reading them, is necessary. Completion of the equipment and schedule of tests is under development.

\section{Acknowledgement}

This work is supported by the Framework Programme for Research and Innovation Horizon 2020 under grant agreement n. 636834 (DISIRE). 


\section{References}

1. B. Bazan, E. Kasinska-Pilut, M. Garbacki, A. Bazan-Krzywoszanska, in Proceedings of the Mineral Engineering Conference MEC2014 (2014)

2. A. Konieczny et al., Gornictwo i geologia, 6(2) (2011)

3. A. Konieczny, B. Bazan, in Proccedings of MEI Conference Comminution (2012)

4. DISIRE Newsletter, 2 (2015)

5. P.Tello, R.Weerdmeester, SPIRE ROADMAP Consultation document (2013)

6. Desire project home page, http://spire2030.eu/disire (2015)

7. FloVis - Wizyjny System Optymalizacji Sterowania Procesami Flotacji http://www.ameplus.pl (2014) 